\title{
Elastic-plastic fracture analysis of anisotropy effect on AA2050-T84 alloy at different temperatures: a numerical study
}

\author{
Nagaraj Ekabote, Krishnaraja G. Kodancha, P. P. Revankar \\ School of Mechanical Engineering, KLE Technological University, Hubballi, India \\ ekabotenagaraj@gmail.com,krishnaraja@kletech.ac.in,pp_revankar@kletech.ac.in
}

\begin{abstract}
The third generation Al-Li alloy AA2050-T84 is widely used in aircraft applications due to its lightweight and significant mechanical properties. The anisotropic variations of tensile and compression properties of this alloy at various temperatures are substantial. In this work, the variations of the J-integral, CTOD, and Plastic Zone Size (PZS) due to anisotropy of a 4-inch thick AA2050-T84 plate at ambient and cryogenic temperatures were studied numerically by using Compact Tension $(\mathrm{C}(\mathrm{T}))$ specimen. The material anisotropy resulted in fracture and constraint parameter variation for Mode-I constant load. Numerical results indicated a decrease in crack driving parameters and a constraint parameter with the decrease in temperature at the plate surface and central location. Plate surface locations appear to be isotropic for both temperatures under elastic-plastic fracture analyses as crack driving parameters were almost identical. The temperature effect is more on constraint as the normalized PZS values at ambient temperature have been twice that of cryogenic temperature. The isotropic behavior of a plate under sub-zero temperature makes the plate suitable for cryogenic temperature applications.
\end{abstract}

KeYwords. AA2050-T84 Al-Li alloy; J-integral; CTOD; Constraint parameter; Plastic Zone Size.

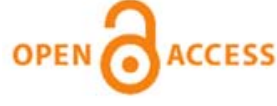

Citation: Ekabote, N., Kodancha, K. G., Revenkar, P. P., Elastic-plastic fracture analysis of anisotropy effect on AA2050-T84 alloy at different temperatures: a numerical study, Frattura ed Integrità Strutturale, 59 (2022) 78-88.

Received: 02.09 .2021

Accepted: 30.09 .2021

Published: 01.01 .2022

Copyright: (C) 2022 This is an open-access article under the terms of the CC-BY 4.0, which permits unrestricted use, distribution, and reproduction in any medium, provided the original author and source are credited.

\section{INTRODUCTION}

A 1-Li alloys are popular in aircraft and space applications due to their significant mechanical properties and lightweight compared to conventional aluminum alloys [1]. Aircraft applications have withdrawn use of $2^{\text {nd }}$ generation $\mathrm{Al}-\mathrm{Li}$ alloys owing to their anisotropic mechanical behavior, lower fracture toughness, and thermal instability induced lower toughness $[1,2,3]$. The high Lithium weight percentage in Al-Li alloy has been the primary cause of these limitations. The innovative processing techniques of Lithium addition to aluminum and restricting its proportion to less than $2 \%$ has led to emergence of $3^{\text {rd }}$ generation Al-Li alloys. The Commercial aircraft and Space shuttle involve critical parts necessitating the use of AA2050-T84 alloy, a $3^{\text {rd }}$ generation Al-Li alloy [3, 4].

Aircraft wing components prone to fracture failure incorporate 'damage tolerance criteria' in their design. The critical material properties and loading patterns become essential in design to avoid fracture failure. The American Society for Testing and Materials (ASTM) standards suggest procedure to obtain fracture toughness for Mode-I loading [5, 6]. These 
standards aim to obtain plane strain fracture toughness ( $\mathrm{K}_{\mathrm{IC}}$ or JIC), assuring a minimum and conservative value at the high constraint.

The fracture toughness depends on specimen geometry, load, and type of specimen, which coined the term constraint. Constraint generated at the crack front is measured through well-defined constraint parameters under Linear Elastic Fracture Mechanics (LEFM) and Elastic-Plastic Fracture Mechanics (EPFM) [7, 8, 9, 10,11,12, 13, 14]. These constraint parameters are defined concerning either the stress field or the displacement field around the crack front. The variation of constraint parameters concerning crack length, specimen thickness, and load variations are well documented for different standard specimens. Moreover, selecting standard methods and specimen types to obtain fracture toughness depends on the constraint present at the component level $[15,16]$.

Material anisotropy was the primary concern for the withdrawal of $2^{\text {nd }}$ generation Al- $\mathrm{Li}$ alloys in aircraft applications. It was observed that anisotropy played a prominent role in the fracture toughness of aircraft components made of $\mathrm{Al}-\mathrm{Li}$ alloys [1,4]. It also revealed that the AA2050-T84 plate of 4-inch exhibited variation in tensile, compression, and fracture toughness to a significant level [4]. Researchers have opined that wing parts, such as spars and ribs fabricated from AA2050-T84 behave differently due to anisotropy under the same load. The constraint variation due to material anisotropy is scarcely reported in the literature, and is limited to specimen thickness, crack length, specimen type, and load conditions.

Hafley et al. [4] experimentally evaluated the 4-inch AA2050-T84 alloy plate performance and discussed its applicability to the cryogenic propellent tanks used for heavy-lift launch vehicles. The experimental comparison between AA2195-T8 and AA2050-T84 for tensile, compression, and fracture responses was investigated. The tensile behavior of the AA2050-T84 alloy at room and cryogenic temperatures exhibited anisotropic nature. However, the reported experimental fracture toughness tests as per ASTM test requirements at both temperatures were invalid. The likely reason for invalid fracture toughness experiments can be related to crack tip/front constraint variations, due to material anisotropy. Chemin et al. [17] reported anisotropy through the valid fracture toughness tests on 2-inch AA2050-T84 plate at different orientation and temperatures. The anisotropic behavior was attributed to state of stress variation at crack influenced by grain properties. Hence, anisotropy of 4-inch AA2050-T84 plate behavior needs numerical fracture constraint analyses based on tensile test results of Hafley et al [4]. The experimentation needs high investment and more time, therefore researchers prefer numerical analysis.

This work emphasizes on crack driving parameters like J-integral and Crack Tip Opening Displacement (CTOD) analyzed for 4-inch AA2050-T84 plate. The through-thickness locations and orientations at ambient and cryogenic temperatures for a constant Mode-I load were studied using Abaqus software. The tensile properties for preprocess stage of simulation were adopted from Hafley et al. [4]. Plastic Zone Size (PZS) parameter was used to analyze the constraint variation at specified conditions. The suitability of 4-inch AA2050-T84 plate for cryogenic application was verified on the basis of anisotropy as a governing factor in crack driving and constraint parameter variations.

\section{NOMENCLATURE, SPECIMEN AND MATERIAL PROPERTY}

A ccording to ASTM E1820-20b, the fracture toughness depends on the orientation and location of the specimen extracted from the plate [6]. In the present analyses, the primary directions of the 4-inch AA2050-T84 alloy plate considered are rolling direction (L), transverse direction (T), and short transverse direction (S). The 4-inch AA2050-T84 alloy plate rolling direction is parallel to the $\mathrm{L}$ direction and possessed a larger dimension than the other two ( $\mathrm{T}$ and S) directions. The different plate orientations for fracture study considered were L-T, T-L, and S-T, as shown in Fig. 1. For instance, fracture specimen L-T orientation indicates loading in the $\mathrm{L}$ direction and crack propagation in the $\mathrm{T}$ direction. In the S-T plate orientation for 4-inch plate thickness, only one fracture specimen was possible with dimensions considered in line with experimental tests [4].

As indicated in Fig. 1, $\mathrm{t}$ is the plate thickness (in this case 4-inch), making the $\mathrm{t} / 2$ at its center ( 2 inches), $\mathrm{t} / 6$ at outer plate surfaces. The various plate orientations and locations at ambient $\left(24^{\circ} \mathrm{C}\right)$ and cryogenic $\left(-195^{\circ} \mathrm{C}\right)$ temperatures were considered for the fracture analyses. ASTM 1820- 20b recommends two high constraint specimens viz. Single Edge Bend $(\mathrm{SE}(\mathrm{B}))$ and Compact Tension $(\mathrm{C}(\mathrm{T}))$ for the measurement of fracture toughness [6]. The $\mathrm{C}(\mathrm{T})$ specimen assures lower bound toughness value compared to SE(B) and suited for primary structures of aircraft applications [1]. Fig. 2 shows the $\mathrm{C}(\mathrm{T})$ specimen used for current fracture analyses adopting width $(\mathrm{W})=25.4 \mathrm{~mm}$, crack length $(\mathrm{a})=12.7 \mathrm{~mm}$ and thickness $(\mathrm{B})=12.7 \mathrm{~mm}$ in compliance to ASTM 1820-20b [6]. 
The material chemical composition constituted copper $(3.3 \%$ to $3.4 \%$ ) as the primary alloying element with lithium (less than 1\%) added to introduce desirable properties [3]. The density reduction by almost 3\% and rise in Young's modulus by $6 \%$ compared to conventional aluminum alloys were noticed $[1,3]$.

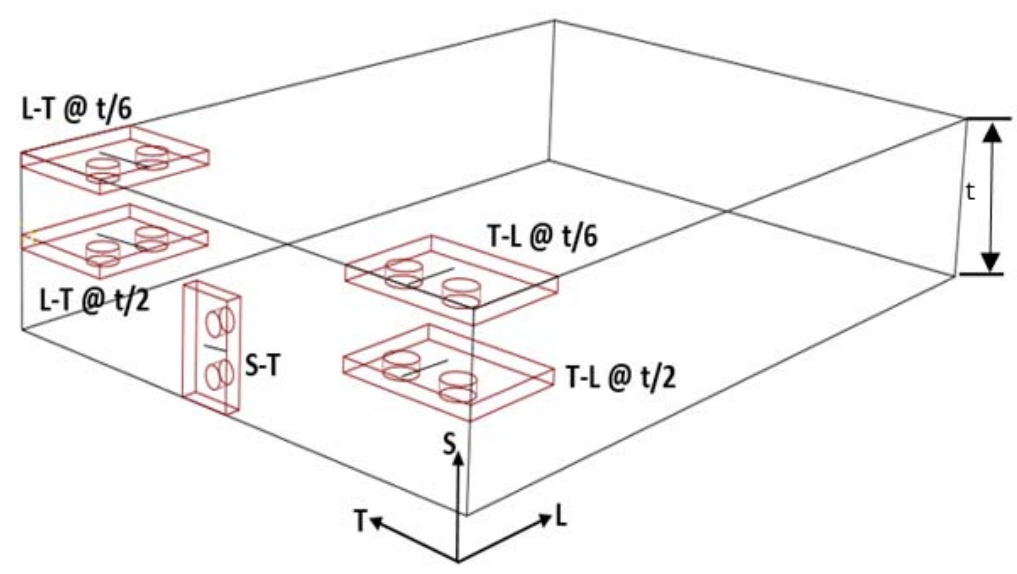

Figure 1: Various Orientation and Location of Fracture Specimens in a 4-inch AA2050-T84 Plate.

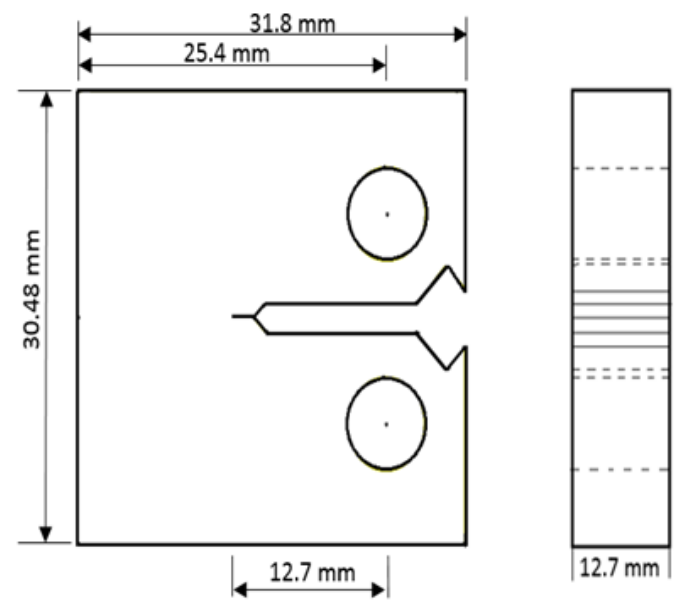

Figure 2: $\mathrm{C}(\mathrm{T})$ Specimen.

The reported experimental tensile properties (shown in Tab. 1) based on Hafley et al. [4] were adopted for different orientations and locations of the plate at ambient $\left(24^{\circ} \mathrm{C}\right)$ and cryogenic $\left(-195^{\circ} \mathrm{C}\right)$ temperatures for Finite Element $(\mathrm{FE})$ analyses. Tab. 1 shows the average tensile properties at various orientations and locations of the 4-inch AA2050-T84 plate [4]. Diverse average tensile properties in different orientations and locations were reported for both ambient and cryogenic test temperature. Anisotropic tensile behavior characterized by plate location and orientation at different temperatures becomes essential in designing spars and ribs. The damage tolerance criterion-based design accounts for anisotropy in the spars and ribs of the aircraft wing during the fracture analysis.

\begin{tabular}{cccccc}
\hline $\begin{array}{c}\text { Temperature } \\
\left({ }^{\circ} \mathrm{C}\right)\end{array}$ & $\begin{array}{c}\text { Plate } \\
\text { Orientation }\end{array}$ & $\begin{array}{c}\text { Specimen } \\
\text { location }\end{array}$ & $\begin{array}{c}\sigma_{\mathrm{ys}} \\
(\mathrm{MPa})\end{array}$ & $\sigma_{\mathrm{ut}}(\mathrm{MPa})$ & $\mathrm{E}(\mathrm{GPa})$ \\
& $\mathrm{L}$ & $\mathrm{t} / 6$ & 486.77 & 509.52 & 74.46 \\
24 & & $\mathrm{t} / 2$ & 515.04 & 546.06 & 75.15 \\
(Ambient) & $\mathrm{T}$ & $\mathrm{t} / 6$ & 478.5 & 521.93 & 75.15 \\
& $\mathrm{~S}$ & $\mathrm{t} / 2$ & 468.84 & 515.73 & 75.84 \\
& $\mathrm{t}$ & $\mathrm{t} / 2$ & 442.64 & 505.38 & 73.77 \\
\hline & $\mathrm{t} / 6$ & 561.92 & 612.25 & 82.05 \\
-195 & $\mathrm{t} / 2$ & 592.26 & 659.82 & 84.11 \\
$($ Cryogenic $)$ & $\mathrm{T}$ & $\mathrm{t} / 6$ & 550.89 & 631.56 & 82.73 \\
& $\mathrm{~S}$ & $\mathrm{t} / 2$ & 543.99 & 630.18 & 84.12 \\
& $\mathrm{t} / 2$ & 504 & 601.91 & 82.05 \\
\hline
\end{tabular}

Table 1: Tensile properties of 4-inch AA2050-T84 alloy plate [4]

\section{FINITE ELEMENT ANALYSES}

he current work emphasizes 3D elastic-plastic numerical fracture analysis on C(T) specimen for mode-I loading using Abaqus 6.14. The stress and strain curves were adopted from the research work of Hafley et al. [4] for the elastic-plastic fracture analysis. In this work, the material response has been considered to be a multi-linear kinematic hardening type. The material's plastic part's behavior was modelled by taking twenty divisions after the yielding point of the stress-strain curves along with elastic input viz., Young's modulus (E) and Poisson's ratio (v). The material property input into the Abaqus 6.14 for elastic-plastic fracture analysis is adopted as similar to the earlier work of Kudari 
et al. $[14,19]$. The crack driving parameters such as J-integral and Crack Mouth Opening Displacement (CMOD) were extracted directly from ABAQUS 6.14 post-processor [18].

The $\mathrm{C}(\mathrm{T})$ model being symmetric about $\mathrm{y}$-axis was analyzed considering only one-half of it with $\mathrm{a} / \mathrm{W}=\mathrm{B} / \mathrm{W}=0.5$, as shown in Fig. 3. A quadratic 20-node hexahedral (brick) element with reduced integration (C3D20R) was used throughout the model for meshing. A similar kind of element was used in earlier work [19, 20]. The model contains 15910 elements with 71709 nodes. At the crack front, these nodes were collapsed at one end (near the crack tip side) for efficient replication of singularity. At the crack front, 1200 elements with 6013 nodes were created for better accuracy of results.

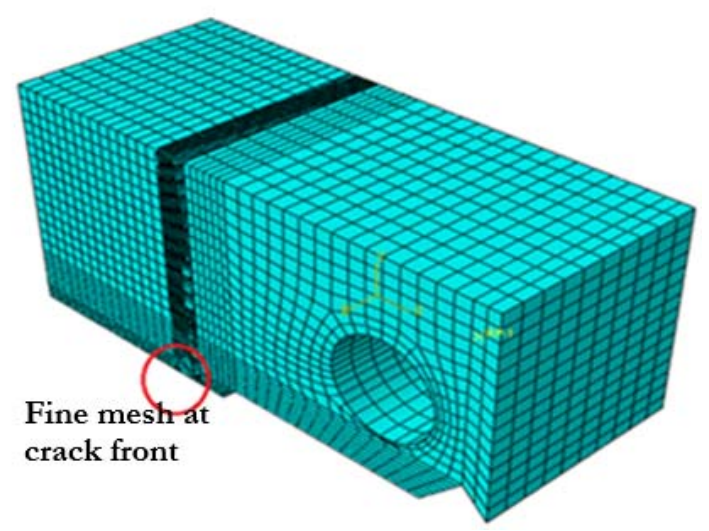

Figure 3: Meshed model of $\mathrm{C}(\mathrm{T})$ specimen

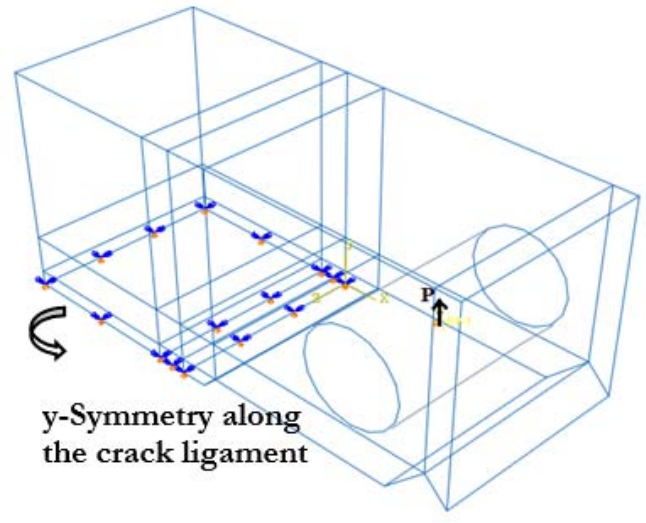

Figure 4: FE Model with Boundary conditions

In the model, along the area of the crack ligament (b), y-symmetry was imposed. A constant concentrated load corresponding to varying load ratio $\left(\mathrm{P}_{\text {applied }} / \mathrm{P}_{\max }\right)$ between 0.1 and 1 with $\mathrm{P}_{\max }$ of $16,000 \mathrm{~N}$ was applied at hole along $\mathrm{y}-$ direction for all numerical analyses. The applied stress $\left(\sigma_{\text {applied }}\right)$ is calculated for $\mathrm{C}(\mathrm{T})$ specimen by using the relation mentioned in the earlier work of A. H. Priest [21]. The $P_{\max }$ of $16,000 \mathrm{~N}$ was selected to keep the stress ratio $\left(\sigma_{\text {applied }} / \sigma_{\mathrm{ys}}\right)$ in between the range 0.4 and 0.5. The wireframe model with boundary conditions shown in Fig. 4 was used for all cases of numerical studies. However, the material properties were assigned as per the specimen's location, orientation, and operating temperature, as mentioned in Tab. 1.

\section{RESULTS AND DISCUSSION}

$\sqrt{1}$ he numerical procedure for the determination of J-integral was validated through an experimental fracture toughness test performed according to ASTM E1820-20b. The current numerical elastic-plastic fracture analysis procedure was adopted and validated from the earlier work [14]. The experimental fracture toughness test resulted in $\mathrm{J}_{\mathrm{IC}}$ of $11.589 \mathrm{~N} / \mathrm{mm}$ at room temperature. The numerical analysis carried out for the same experimental load conditions resulted in the value of J-integral as $11.02 \mathrm{~N} / \mathrm{mm}$. The marginal difference $(<5 \%)$ in values are served as motivation to extend the numerical procedure for further investigations. In the 3-D numerical analysis, the J-integral and CMOD were extracted along the crack front (thickness direction) at room temperature as shown in Figs. 5 and 6.

Fig. 5 indicates the variation of J-integral along the crack front at the ambient temperature of $24^{\circ} \mathrm{C}$ for various plate location and orientation conditions. The peak values of J-integral at crack front center were attributed to the crack tunneling effect [6]. A similar phenomenon of peak J-integral values at the crack front center was observed at a cryogenic temperature of $-195^{\circ} \mathrm{C}$. As expected, the CMOD values are constant along the crack front for all plate orientations. Gentile et al. [13] have performed FE analysis to predict specimen response through crack driving parameters viz. computed J-integral with measured CTOD. In the present work we have also attempted to study the behavior of variation of CTOD on different orientation and locations. Thus, the peak values of J-integral, and CTOD at crack front center were taken up for further analysis at both temperatures.

\section{Effect of plate location}

Crack driving parameters characterized by J-integral and CMOD were extracted in LT, TL, and ST orientations at through-thickness locations of the plate. These parameters relative values provided insight into the behavioral aspects of 
the plate under constant external load subjected to different plate orientations. Figs. 7 and 8 depict them for varying load ratios.

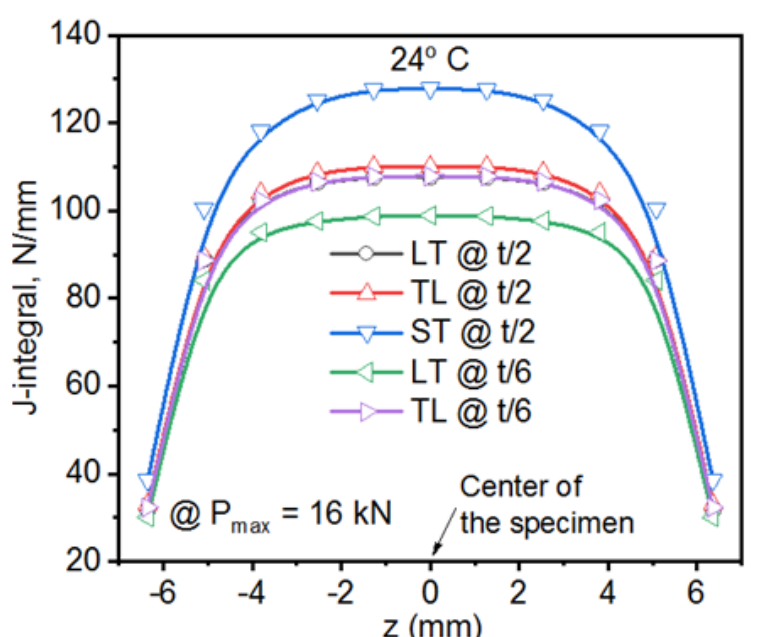

Figure 5: J-integral along the crack front at Ambient temperature.

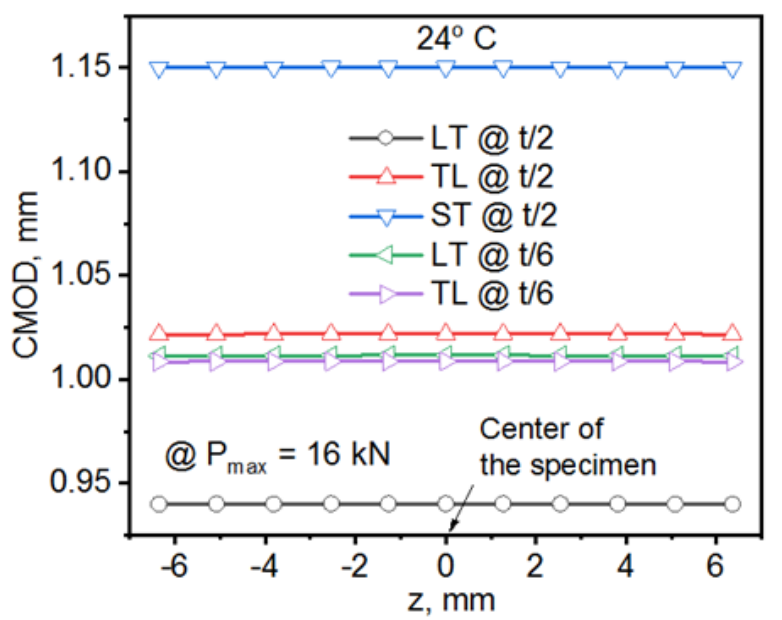

Figure 6: CMOD along the crack front at Ambient temperature.

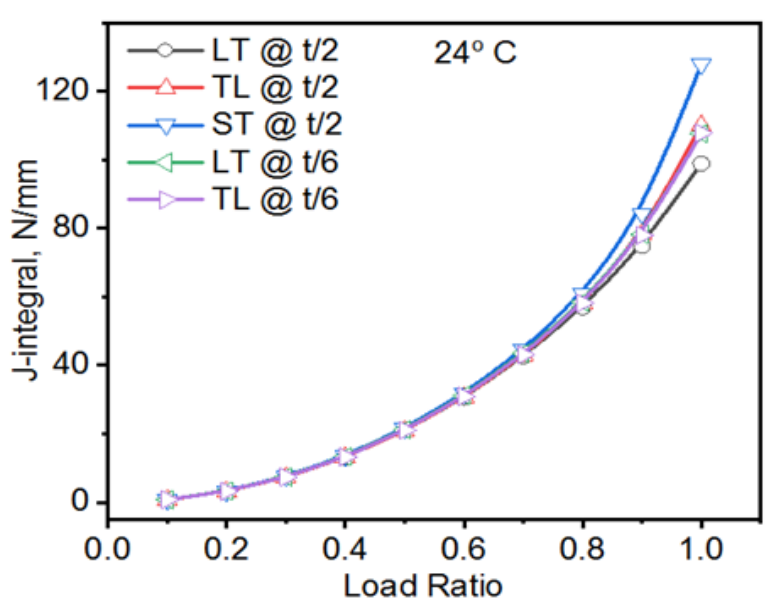

Figure 7: Variation of J-integral for different plate orientation and location at $24^{\circ} \mathrm{C}$

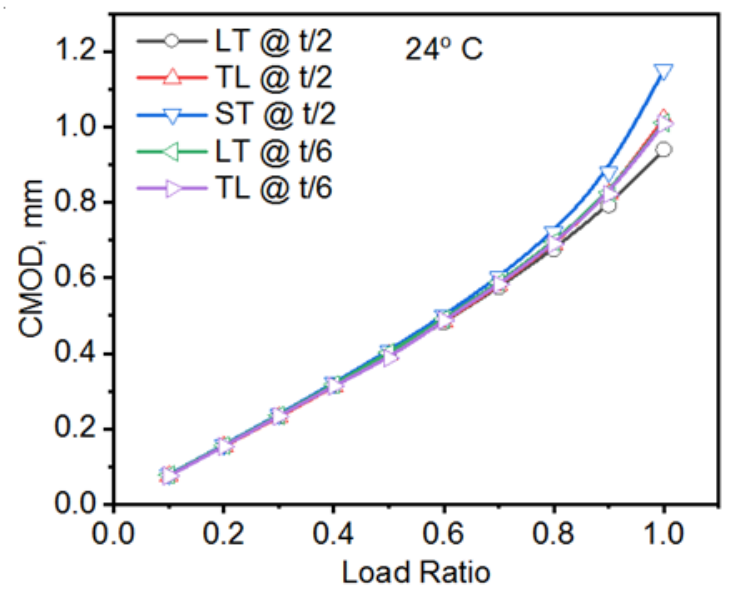

Figure 8: Variation of CMOD for different plate orientation and location at $24^{\circ} \mathrm{C}$

The non-linear nature of J-integral exhibited the increasing order LT-TL-ST, with the highest value recorded for ST orientation at a load ratio greater than 0.4 . The J-integral differed by around $12 \%$ between LT and TL and around $30 \%$ between LT and ST orientations with peak load ratio for unity. Similarly, CMOD value differed by about $8 \%$ at peak load ratio between LT and TL and around 23\% between LT and ST orientations. The value of J-integral and CMOD for LT configuration was higher by $8-9 \%$ at plate center ( $t / 2)$ against plate surface $(t / 6)$. However, it decreased by $2 \%$ in TL orientation at peak load ratio.

Figs. 9 and 10 depict J-integral and CMOD variation for various load ratios at different orientations and locations of the plate for cryogenic temperature. The J-integral and CMOD varied slightly $(4 \%-8 \%)$ exhibiting gradual increase in the LTTL-ST sequence of plate orientations at peak load ratio. Their values at cryogenic temperature increased by $2-4 \%$ from positions $\mathrm{t} / 2$ to $\mathrm{t} / 6$ for LT against less than $1 \%$ for TL orientations at peak load ratios. The anisotropy effect on crack driving parameters was less at cryogenic temperature, confirming with observed in tensile test results of Hafley et al. [4]. CTOD is another important fracture parameter based on displacement at the crack tip/front of the specimen. According to ASTM 1820-20b [6], CTOD is calculated from J-integral value. Figs. 11 and 12 show the CTOD variation for different plate orientations and locations at ambient and cryogenic temperatures. These CTOD variations follow a similar trend displayed by J-integral in Figs. 5 and 7. Plate surface $(t / 6)$ locations are isotropic for both temperatures under fracture analyses as crack driving parameters were almost identical. A similar observation was reported in the tensile behavior of Hafley et al. [4]. The weaker intensities of deformation texture components were due to surface rolling associated with 
lower yield strength. The isotropic properties at $\mathrm{t} / 6$ location at both temperatures make it a congenial material for wing components like spars and ribs over the surface of the AA2050-T84 plate.

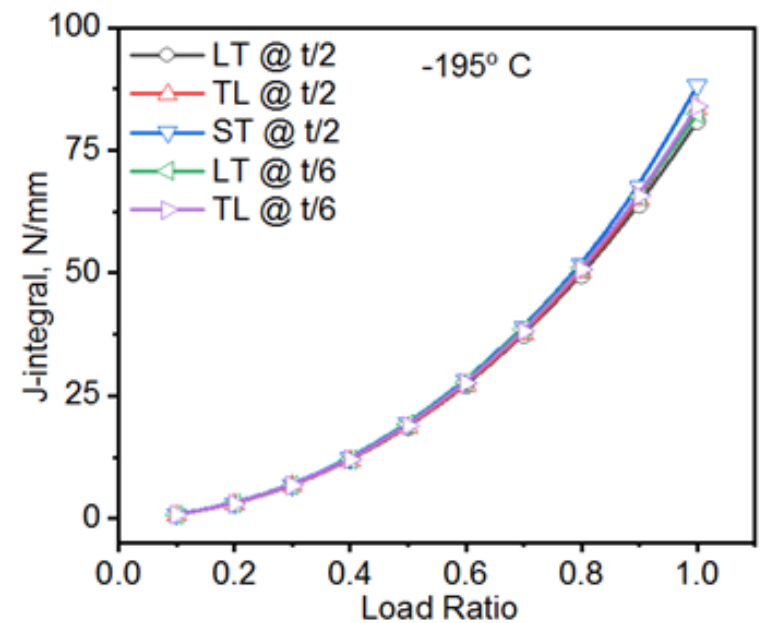

Figure 9: Variation of J-integral for different plate orientation and location at $-195^{\circ} \mathrm{C}$

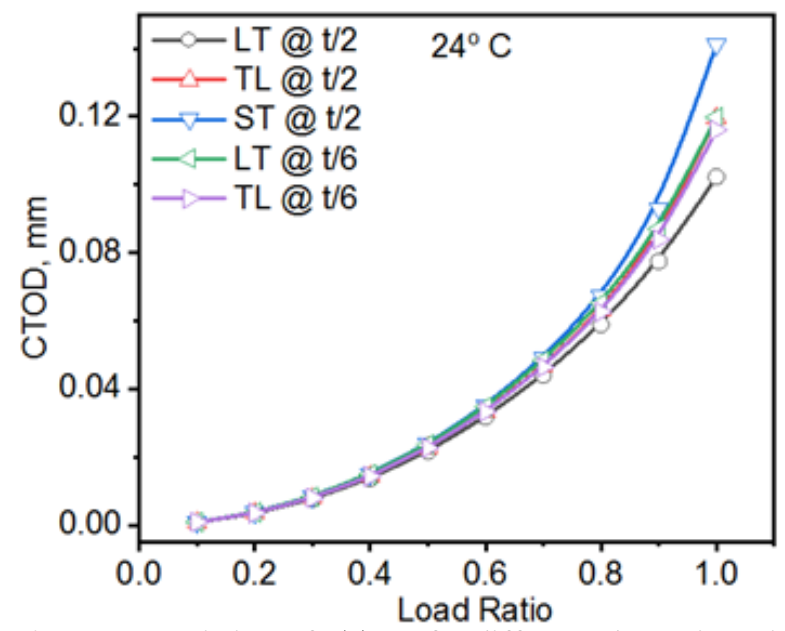

Figure 11: Variation of CTOD for different plate orientation and location at $24^{\circ} \mathrm{C}$

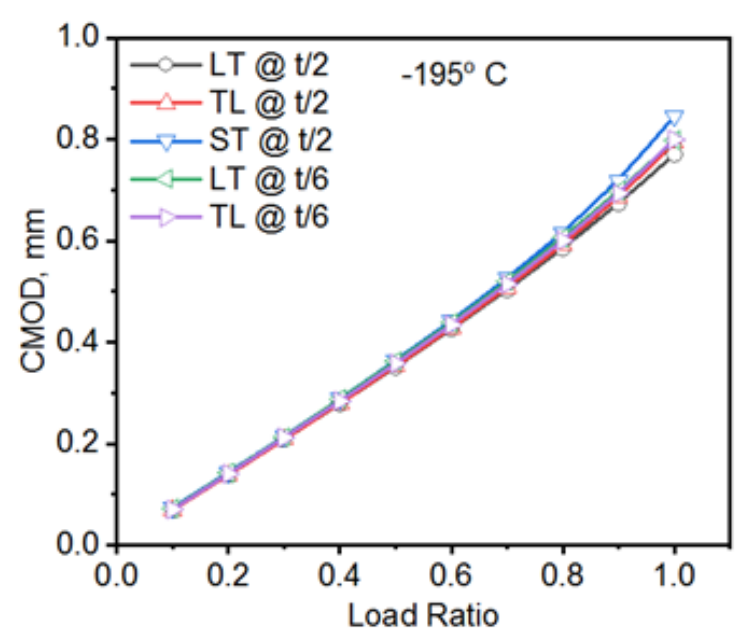

Figure 10: Variation of CMOD for different plate orientation and location at $-195^{\circ} \mathrm{C}$

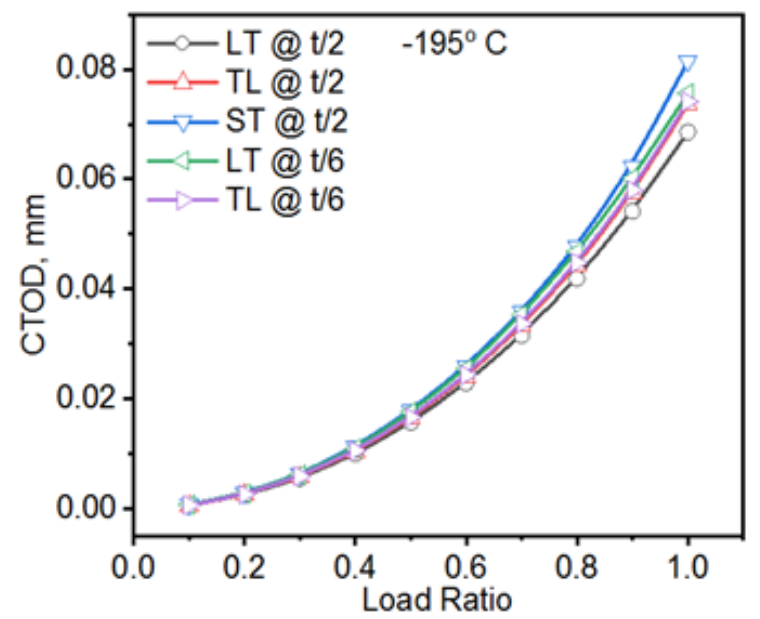

Figure 12: Variation of CTOD for different plate orientation and location at $-195^{\circ} \mathrm{C}$

The location in a plate was quite significant at both temperatures because of appreciable variations in crack driving parameters. However, the plate orientation had a substantial effect at ambient temperature compared to cryogenic temperature. AA2050-T84 plate showed inconsistent fracture behavior concerning locations and orientations at different temperatures being significant for designing aircraft primary wing components. Chemin et al. [17] have observed that the plane strain fracture toughness $\left(\mathrm{K}_{\mathrm{IC}}\right)$ of the 2-inch thick AA2050-T84 alloy material decreased with LT to TL orientation by almost $23 \%$ at ambient temperature. On the contrary, in the present EPFM analyses, J-integral increased by nearly $11 \%$ from LT to TL orientation at a similar temperature. Thus, the TL orientation is more susceptible to fracture failure than the LT under identical load at ambient temperature due to its lower $\mathrm{K}_{\mathrm{IC}}$ value.

\section{Effect of Plate orientation}

The comparison of crack driving parameters at different temperatures was crucial to claim its suitability at cryogenic temperatures. This issue is prominent in the design of space shuttle tanks because of material extraction from different orientations. The variation of crack driving forces at these orientations at various operating temperatures was crucial also for aircraft component damage tolerance design. Figs. 13 to 18 present the variation of J-integral, CMOD and CTOD at different plate locations dependent on plate temperature and orientations. 


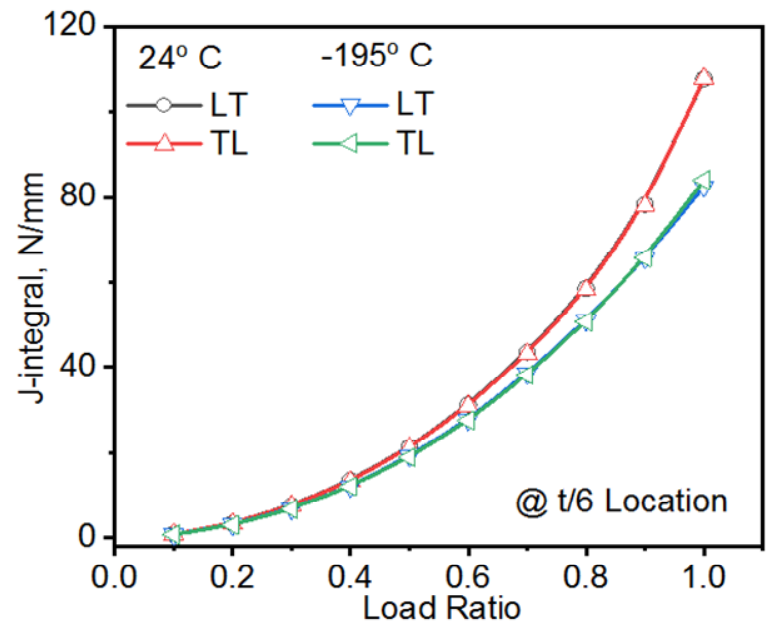

Figure 13: Variation of J-integral for different plate orientation at $\mathrm{t} / 6$ location

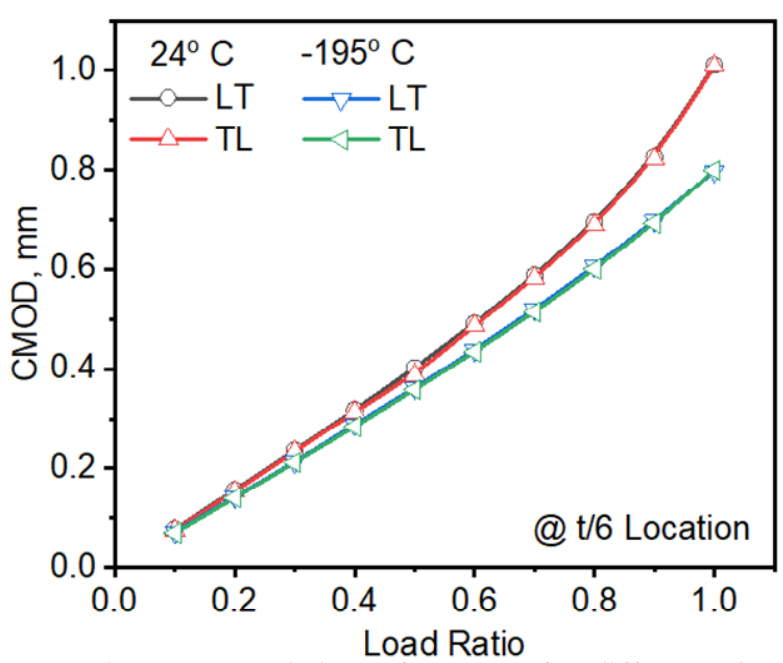

Figure 15: Variation of CMOD for different plate orientation at $\mathrm{t} / 6$ location

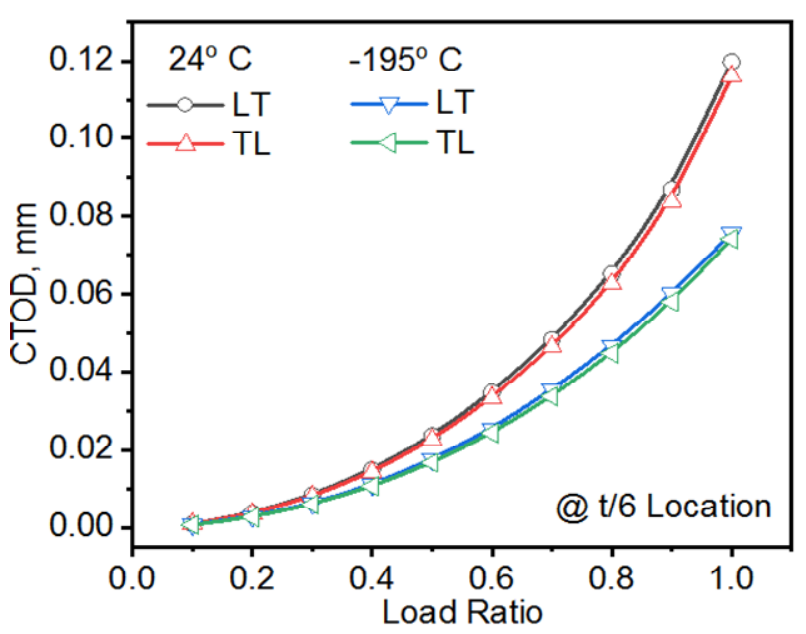

Figure 17: Variation of CTOD for different plate orientation at $\mathrm{t} / 6$ location

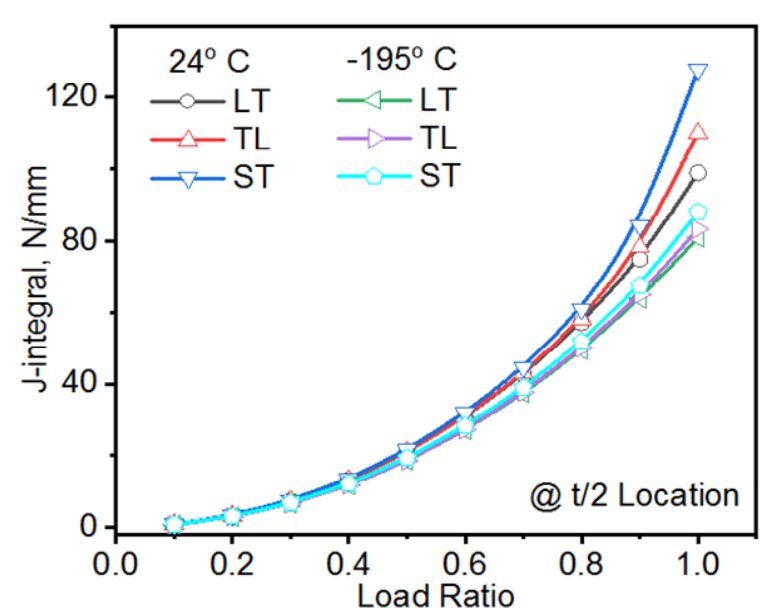

Figure 14: Variation of J-integral for different plate orientation at $\mathrm{t} / 2$ location

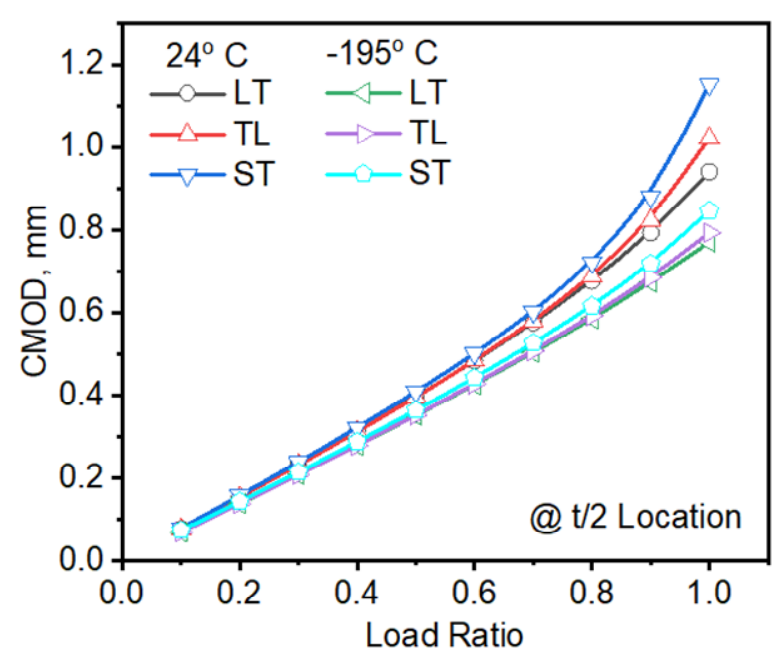

Figure 16: Variation of CMOD for different plate orientation at $\mathrm{t} / 2$ location

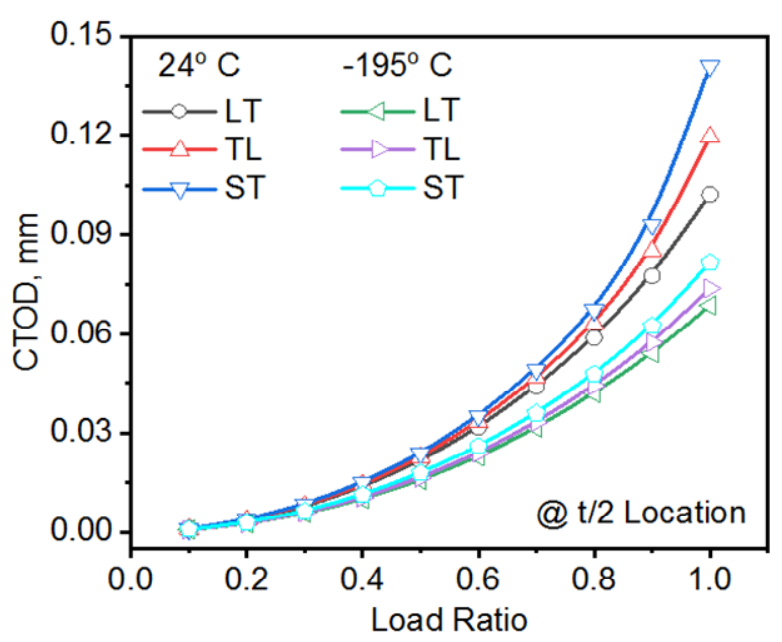

Figure 18: Variation of CTOD for different plate orientation at $\mathrm{t} / 2$ location 
The decrease in J-integral and CMOD was noticed at a cryogenic temperature at both location and plate orientations. The temperature change from ambient to cryogenic leads to the decline by $22 \%, 32 \%$, and $45 \%$ for J-integral values in LT, TL, and ST orientations of $\mathrm{t} / 2$ locations for peak load ratio. Similarly, $28 \%$ of the drop in J-integral at $\mathrm{t} / 6$ locations for both LT and TL orientations were observed for peak load ratio. In Figs. 14 and 16, the specimen extracted at the plate surface $(t / 6)$ was less affected $(<2 \%)$ by orientation at ambient and cryogenic temperatures. From Figs. 13 and 15 , the plate center $(\mathrm{t} / 2)$ location show significant variations in J-integral and CMOD values at ambient conditions only. The Figs. 17 and 18 depict similar trend of CTOD variations to establish a correlation with J-integral. The observed behavior was attributed to resistance for dislocation movement at cryogenic temperature, causing the material to dissipate lower energy [21].

Fracture results at $\mathrm{t} / 6$ location of the plate exhibited isotropic behavior similar to tensile results Hafley et al. [4] at both ambient and cryogenic temperatures. However, the plate center $(t / 2)$ location showed higher anisotropy at ambient temperature than cryogenic temperatures. The anisotropy was attributed to the strain gradients introduced during rolling, resulting in an increased strain in the vicinity of $t / 2$ location [4]. These results strongly support use of AA2050-T84 plate for cryogenic applications.

\section{Effect of anisotropy on PZS}

The modern-day fracture assessment criterion requires data on constraint variation near the crack front and crack driving parameters. Constraint is defined as the restriction to plastic deformation at the crack front [22]. Plasticity around the crack front is measured as plastic zone size and shape, which depend on the in-plane dimension (crack length) and out-ofplane dimension (specimen thickness) [14]. 3D crack front stress tri-axiality fields significantly affect the constraint measured by PZS [19, 23]. The plastic zone shape and size at the crack front are usually helpful to define plane stress and plane strain conditions. PZS is a suitable parameter to measure constraint near the crack under EPFM. The PZS also significantly affects the standard specimen size required for experimental testing of fracture toughness [5, 6]. Since the plastic zone is crucial in EPFM analysis, the anisotropy role will be noteworthy in PZS variation. The present analysis attempts measurement of the constraint variation concerning anisotropy and temperature using normalized PZS $\left(\mathrm{PZS} /\right.$ crack length $\left.=\mathrm{r}_{\mathrm{p}} / \mathrm{a}\right)$ at crack front. PZS measured as per Kudari et al. [14] at the center of the crack front is shown in Fig. 19, and the shape of PZS along the crack front is shown in Fig. 20. Figs. 21 and 22 show the variation of normalized PZS for plate orientation and location at ambient and cryogenic temperatures.

At ambient temperature, normalized PZS for peak load ratio was almost 18\% higher in LT orientation, t/6 location compared to $t / 2$ location. PZS is inversely proportional to the square of the yield stress of the material [18]. Normalized PZS increased with plate orientation in the order of LT-TL-ST in agreement to observations made by Hafley et al. [4] that reported a decrease in yield stress in the order of LT-TL-ST at both locations of the plate. However, the constraint variation between $\mathrm{LT}$ and TL orientation for both temperatures was minimal $(<5 \%)$ at $\mathrm{t} / 6$ location. The minimal difference of yield stress values can be visualized at t/ 6 locations from Tab. 1 for both temperatures. Unlike Figs. 14 and 16, which showed minimal crack driving parameters at the $t / 2$ location of the cryogenic temperature, the normalized PZS difference was substantial for different plate orientations. This trend indicated isotropic behavior at $\mathrm{t} / 6$ plate location for both temperatures, making the AA2050-T84 alloy plate surface suitable for ambient and cryogenic applications.

From Figs. 23 and 24, the effect of plate orientation on normalized PZS at $t / 6$ location for cryogenic temperature was negligible. At cryogenic temperature, the variation of normalized PZS at $\mathrm{t} / 2$ location increased almost $35 \%$ between LT and TL or ST orientations for peak load ratio, respectively. But, at $\mathrm{t} / 6$ location, the constraint variation was minimal $(<5 \%)$ at cryogenic temperature. However, at ambient temperature, the normalized PZS variation was significant for plate location and orientation. At ambient temperature, the variation of normalized PZS at t/2 location increased almost $22 \%$ between LT to TL and 48\% between LT and ST orientations, respectively.

Similarly, at t/ 6 location the constraint variation was almost 4\% between LT and TL orientations at ambient temperature. The temperature effect is remarkable on constraint as the normalized PZS values at ambient temperature were almost twice that of cryogenic temperature. The possible reason for lower values of normalized PZS is the brittle nature of the AA2050-T84 alloy at cryogenic temperature. The observations from crack driving parameters and constraint variation at cryogenic temperature strongly suggest that the plate orientation effect nullified and almost behaved as isotropic material at $\mathrm{t} / 6$ location (plate surface). 


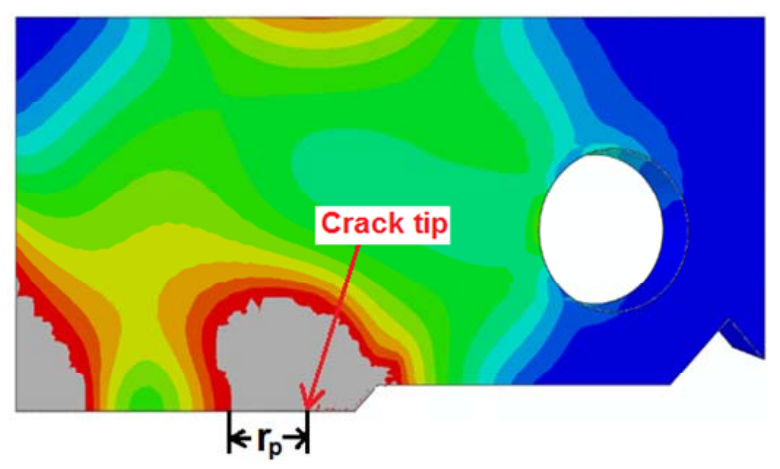

Figure 19: PZS ( $\left.\mathrm{r}_{\mathrm{p}}\right)$ measurement at crack center

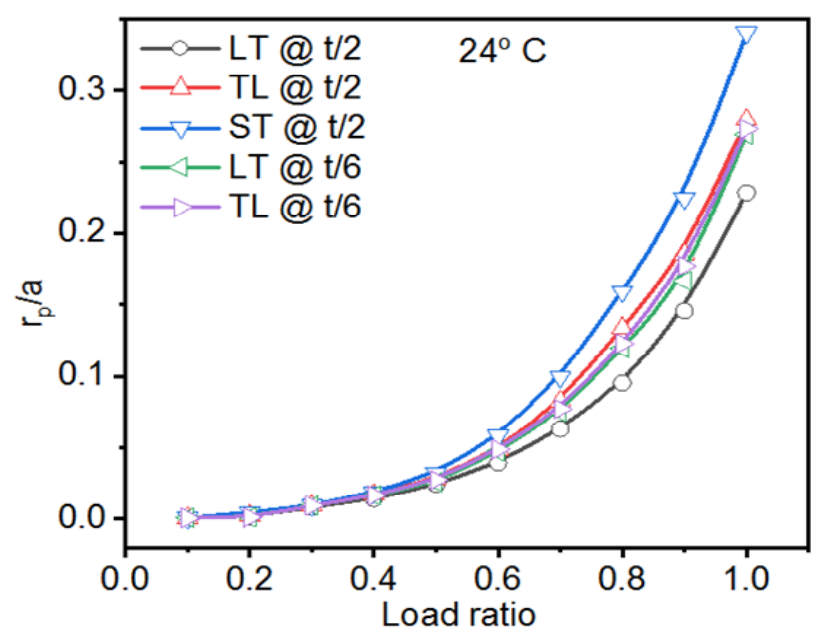

Figure 21: Variation of Normalized PZS for different plate orientation and location at $24^{\circ} \mathrm{C}$

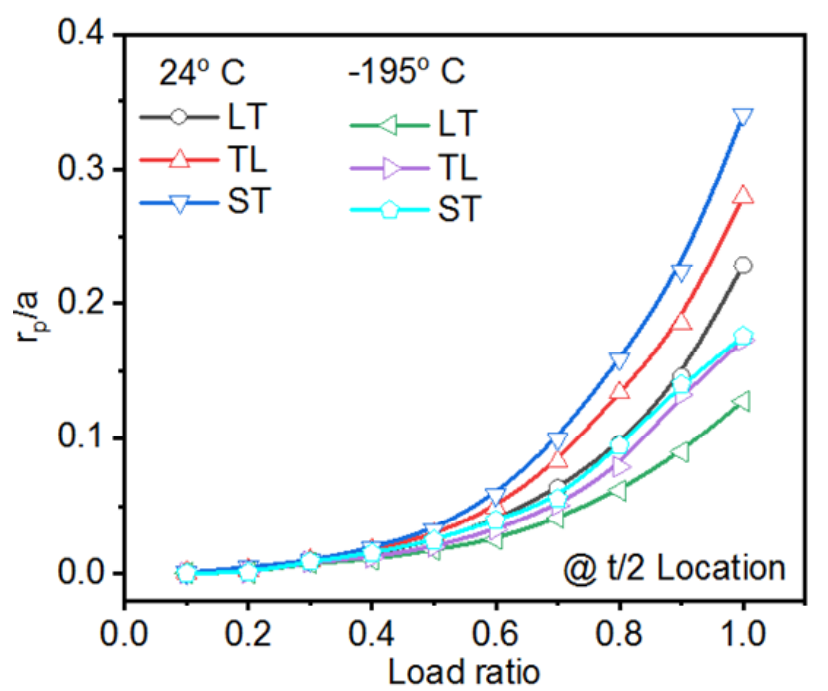

Figure 23: Variation of Normalized PZS for various plate orientation at $\mathrm{t} / 2$ location

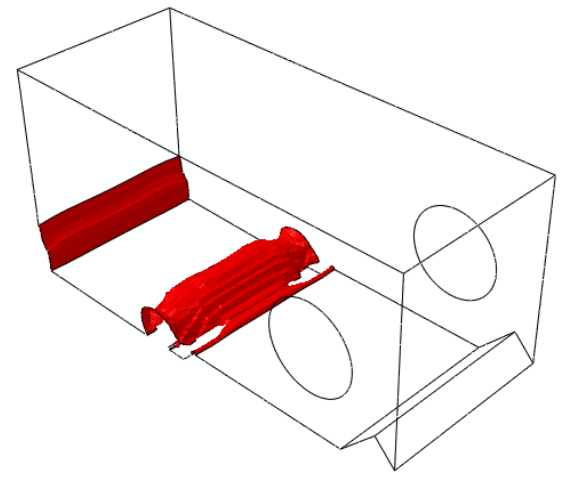

Figure 20: Plastic Zone Shape along the crack front

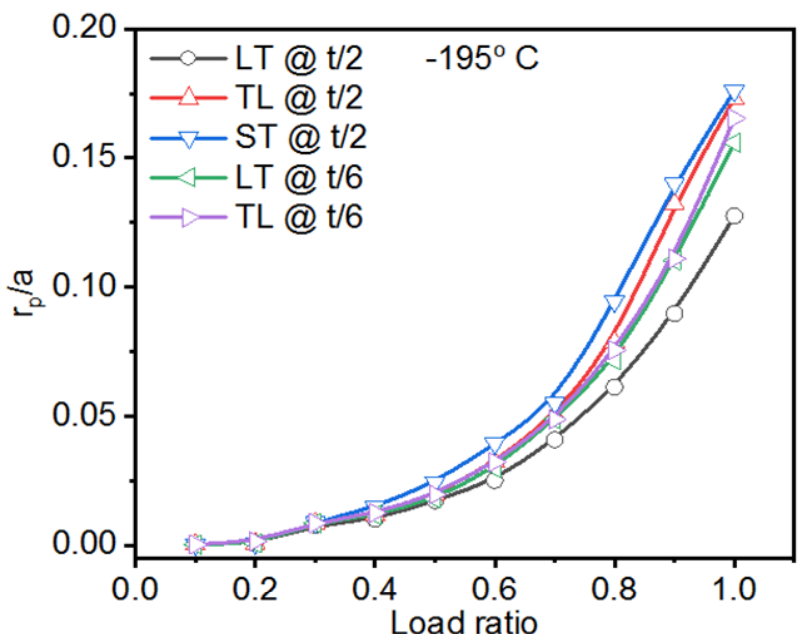

Figure 22: Variation of Normalized PZS for different plate orientation and location at $-195^{\circ} \mathrm{C}$

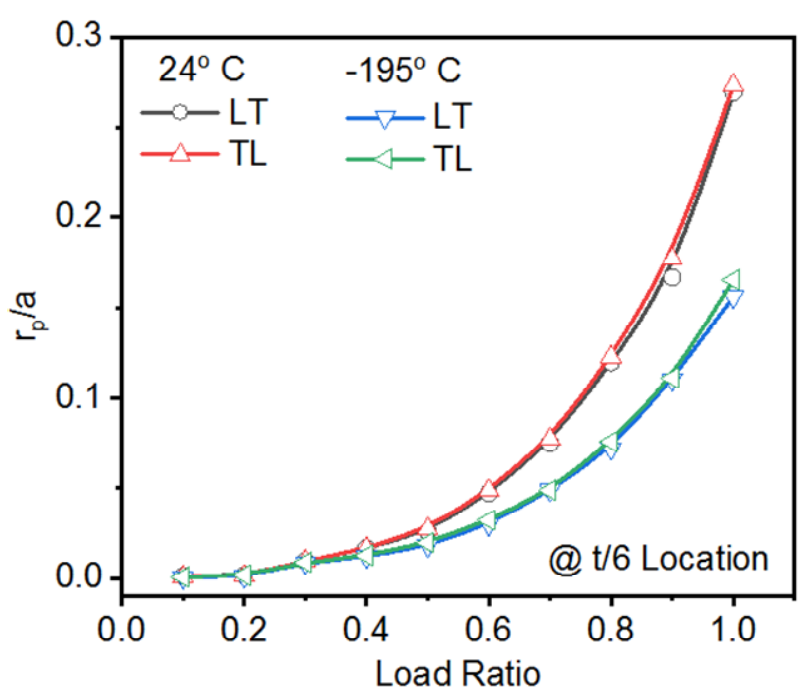

Figure 24: Variation of Normalized PZS for various plate orientation at $\mathrm{t} / 6$ location 


\section{CONCLUSION}

he computational investigations on the AA2050-T84 specimen revealed the following conclusive remarks. A 4inch AA2050-T84 alloy plate behavior under mode-I loading using C(T) specimen was analyzed in the present study. The effect of anisotropy on fracture and constraint parameters in J-integral, CTOD, CMOD and PZS was studied at ambient and cryogenic temperatures. On account of rolling, plate surface $(\mathrm{t} / 6)$ location elongated more and had higher crack driving parameters than mid-plate location $(t / 2)$ under identical mode-I loading. Plate orientation had a negligible effect on crack driving parameters at both ambient and cryogenic temperatures. However, the constraint parameter, PZS variation, was significant. Both crack driving parameters and PZS increased in the order of LT-TL-ST for ambient and cryogenic temperatures.

The studies based on through-thickness variation indicated that crack driving parameters were maximum at plate surface (t/6) locations for both temperatures. The crack driving parameters were twice at the surface of the plate as compared to the mid-plate location. Constraint parameter PZS was higher at plate surface (t/6) ambient temperature than mid-plate $(t / 2)$ location. However, the effect of plate location on constraint parameter PZS was minimal at cryogenic temperature. The crack driving parameters exhibited a falling trend with decreased test temperature. The effect of temperature on crack driving parameters and PZS was maximum at the plate surface compared to the mid-plate location.

The plane strain fracture toughness (KIC) of the AA2050-T84 alloy plate reduced with a decrease in temperature along LT orientation and was almost independent of orientation in TL [17]. The results obtained in the current work are helpful in deciding the location and orientation of the aircraft wing component extraction from AA2050-T84 alloy plate, as crack driving parameters and constraint variation were significant to anisotropic plate properties at different temperatures. The isotropic behavior at the t/6 location under sub-zero temperature made the plate surface suitable for cryogenic temperature applications.

\section{ACKNOWLEDGMENTS}

LE Technological University has partially supported this work under "Capacity Building Project" grants. Authors thank KLE Society and KLE Technological University, Hubballi, for the funds and support.

\section{REFERENCES}

[1] Prasad, N. E., Gokhale, A. and Wanhill, R. J. H. (Eds.). (2013). Aluminum-lithium alloys: processing, properties, and applications, Butterworth-Heinemann. DOI: 10.1016/C2012-0-00394-8.

[2] Lynch, S.P., Muddle, B.C. and Pasang, T., (2002). Mechanisms of brittle intergranular fracture in Al-Li alloys and comparison with other alloys, Philosophical Magazine A, 82(17-18), pp. 3361-3373.

DOI: $10.1080 / 01418610208240447$.

[3] Rioja, R. J. and Liu, J. (2012). The evolution of Al-Li based products for aerospace and space applications, Metallurgical and Materials Transactions A, 43(9), pp.3325-3337. DOI: 10.1007/s11661-012-1155-z.

[4] Hafley, R. A., Domack, M. S., Hales, S. J. and Shenoy, R. N. (2011). Evaluation of Aluminum Alloy 2050-T84 Microstructure and Mechanical Properties at Ambient and Cryogenic Temperatures, NASA Langley Research Center. Report number: NASA/TM-2011-217163.

[5] ASTM E399-20a, Standard Test Method for Linear-Elastic Plane-Strain Fracture Toughness of Metallic Materials, ASTM International, West Conshohocken, PA, 2020. DOI: 10.1520/E0399-20A.

[6] ASTM E1820-20b, Standard Test Method for Measurement of Fracture Toughness, ASTM International, West Conshohocken, PA, 2020. DOI: 10.1520/E1820-20B.

[7] Gupta, M., Alderliesten, R. C. and Benedictus, R. (2015). A review of T-stress and its effects in fracture mechanics, Engineering Fracture Mechanics, 134, pp.218-241. DOI:10.1016/j.engfracmech.2014.10.013.

[8] Moattari, M. and Sattari-Far, I. (2017). Modification of fracture toughness Master Curve considering the crack-tip Qconstraint, Theoretical and Applied Fracture Mechanics, 90, pp. 43-52. DOI: 10.1016/j.tafmec.2017.02.012. 
[9] Yang, J., Wang, G. Z., Xuan, F. Z. and Tu, S. T. (2013). Unified characterization of in-plane and out-of-plane constraint based on crack-tip equivalent plastic strain, Fatigue \& Fracture of Engineering Materials \& Structures, 36(6), pp.504-514. DOI: 10.1111/ffe.12019.

[10] Vasco-Olmo, J. M., Díaz, F. A., James, M. N., Christopher, C. J. and Patterson, E. A. (2017). Experimental methodology for the quantification of crack tip plastic zone and shape from the analysis of displacement fields, Frattura ed Integrita Strutturale, 11(41), pp.166-174. DOI: 10.3221/IGF-ESIS.41.23.

[11] Xu, J. Y., Wang, G. Z., Xuan, F. Z. and Tu, S. T. (2018). Unified constraint parameter based on crack-tip opening displacement, Engineering Fracture Mechanics, 200, pp.175-188. DOI: 10.1016/j.engfracmech.2018.07.021.

[12] Matvienko, Y., (2019). Comparison of the constraint parameters in elastic-plastic fracture mechanics. Frattura ed Integrità Strutturale, 13(49), pp.36-43. DOI:10.3221/IGF-ESIS.49.04.

[13] Gentile, D., Persechino, I., Bonora, N., Iannitti, G. and Carlucci, A. (2014). Use of Circumferentially Cracked Bar sample for CTOD fracture toughness determination in the upper shelf regime. Frattura ed Integrità Strutturale, 8(30), pp. 252-262. DOI: 10.3221/IGF-ESIS.30.32.

[14] Kudari, S. K., Maiti, B. and Ray, K. K. (2009). Experimental investigation on possible dependence of plastic zone size on specimen geometry. Frattura ed Integrità Strutturale, 3(7), pp. 57-64. DOI: 10.3221/IGF-ESIS.07.04.

[15] Chiesa, M., Nyhus, B., Skallerud, B. andThaulow, C. (2001). Efficient fracture assessment of pipelines. A constraintcorrected SENT specimen approach, Engineering Fracture Mechanics, 68(5), pp.527-547. DOI: 10.1016/S0013-7944(00)00129-6.

[16] Ekabote, N., Kodancha, K.G. and Kudari, S.K., (2021). Suitability of standard fracture test specimens for low constraint conditions. IOP Conf. Ser.: Mater. Sci. Eng., 1123, 012033, DOI: 10.1088/1757-899X/1123/1/012033.

[17] Chemin, A. E. A., Afonso, C. M., Pascoal, F. A., Maciel, C. I. D. S., Ruchert, C. O. F. T. and Bose Filho, W. W. (2019). Characterization of phases, tensile properties, and fracture toughness in aircraft-grade aluminum alloys, Material Design \& Processing Communications, 1(4), pp.1-13. DOI:10.1002/mdp2.79.

[18] ABAQUS 6.14-1. (2004) Hibbitt, Karlsson \& Sorensen, Inc.

[19] Kudari, S. K. and Kodancha, K. G. (2008). Effect of specimen thickness on plastic zone. 17th European conference on fracture, Brno, Czeck Republic.

[20] Moreira, P. M. G. P., Pastrama, S. D. and de Castro, P. M. S. T. (2009). Three-dimensional stress intensity factor calibration for a stiffened cracked plate. Engineering fracture mechanics, 76(14), pp. 2298-2308, DOI: $10.1016 /$ j.engfracmech.2009.07.003.

[21] Priest, A. H. (1975). Experimental methods for fracture toughness measurement. Journal of Strain Analysis, 10(4), pp. 225-232. DOI: 10.1243/03093247V104225.

[22] Yuan, H. and Brocks, W. (1998). Quantification of constraint effects in elastic-plastic crack front fields, Journal of the Mechanics and Physics of Solids, 46(2), pp. 219-241. DOI: 10.1016/S0022-5096(97)00068-9.

[23] Caputo, F., Lamanna, G. and Soprano, A. (2013). On the evaluation of the plastic zone size at the crack tip, Engineering Fracture Mechanics, 103, pp. 162-173. DOI: 10.1016/j.engfracmech.2012.09.030. 